\title{
Difficulties that Student Encounter When Learning the Culture of Target Language (English)
}

\author{
Enkeleda Jata \\ European University of Tirana \\ enki_jata@yahoo.it
}

Abstract

\begin{abstract}
Nowadays students are expected to be prepared for the 21st century. It has been widely accepted that culture is a very important element in learning a foreign language. It is impossible to learn a new language without tackling its culture. Learning a foreing laguage should not be focused only on grammatical issues, or on the vocabulary of target language but it should combined with the culture as well. Students should be taught to have a succesful communication with individuals from different culture. They should understand that they belong to different cultural background, accept and respect others culture. This article analyses the difficulties they encounter in learning the culture of target language. Here is provided detailed analyses of what should be taught.
\end{abstract}

Keywords: culture, students, curricula

\section{Introduction}

When learning a foreign language we start unconsciously to pick up its culture. In order to have an efficiant communication it is important to learn the culture of the target language as well. Knowing to speak a language at its highest level does not mean that one has the proper social and cultural competences for an efficient communication.

All of us, without exception, have travelled abroad and might have gone through differrent cultural problems that have led to conflicts, prejudices and misunderstandings. Each individual belongs to a definite cultural group and at the moment they face individuals of different cultures can encounter difficulties to adapt and communicate. Cultural differences can cause cultural confusion and misunderstanding. Learning a foreign language implies talking and understanding it and without a proper use of the target language in the respective cultural context we cannot achieve a good communication.

By learning to respect, accept and appreciate the individuals belonging to different cultures we can also learn how to be good citizens in a pluralist society. Culture is taught by the family, friends and community where we live and affect the way we act and think. Currently, English is the top used language in the world. People all over the world learn English for definite aims.

Following different studies it results that students encounter many difficulties in adapting and learning the culture of target language. This due to academic curricula which do not provide teaching of intercultural competence. Students do not have the right capacities and knowledge on how to learn the target language culture.

\section{Data decription}

To give answer to these questions were distributed a questionary to the students at Bedër University. The questionary was adopted by Lies Secu (An international investigation) but with a few changes in order to be adoptable to the students.An estimated amount of 80 students in Bachelor Degree answered a series of questions with regard to intercultural competence. Answers are taken from different students of first, second and third year of Bachelor Degree. Within the questionnaire were included questions with alternatives and open questions. This is a qualitative study to learn more on the opinion, attitudes, problems etc. that students encounter during the teaching of English culture. 


\section{Problemes encounterd by the students.}

In Albania, students have many difficulties in learning the culture of English-speaking countries and cultural differences that exist can cause problems during the teaching classes of foreign language. Use of words in English is defined by the linguistic and cultural context. When learning a word we should also learn about the cultural background of that word to have a correct meaning. During the questionnaire it came out that information of students on English-speaking countries comes mainly from the internet, movies, music etc. meaning that information received at school is very little.

Some of the problems they encounter are:

- Students have a tendency to use grammatical knowledge of mother language and apply them to the target language.

- Students have a tendency to transfer their cultural knowledge in order to understand the context of target language.

- They have very limitied opportunities to communicate and interact with individuals from English-speaking countries.

- They are not given the opportunity to learn the jargon.

- School materials are very few.

- In school curricula learning of culture is a third-hand element.

- Serious lack of approaches on how to solve cultural conflicts or to adapt to individuals of different cultures.

- Serious lack of practical skills.

- Cultural differences affect:

- in the communication between individuals starting from greetings, giving or taking of presents, meals etc.

- way of perception of the message.

- in what students expect hear.

- Why is it neccesary to be taught:

- better understanding a language.

- learning a new culture makes you reflect on your culture.

- learning a new culture gives you an opportunity to make a comparison between your culture and target language culture.

- affecting the increase of interest and motivation to learn English.

By noticing the difference among Albanian and English, we should understand that when learning a foreign language we should not simply learn vocabulary or grammar, but also the way of thinking and of structuring the senteces that is dependent on English language features. Students need to learn how to communicate and how to discover their own world. For this reason, each academic topic should be organised in a way to develop interpretative and analitic abilites. Of course, grammar and vocabulary have a special importance but should not stop simply at this.

Nowadays, the teacher is not the only person responsible to encourage the teaching of culture but it is required a collaboration between students and teachers. A good way is to conduct dialogues and debates on the topics provided in school texts or they can be found in other extra materials. Dialogues and debates help in gaining insight on students' perspective, experience exchange.

\section{Analysing some of the data from the questionnare regarding the difficulties in learning the culture.}

In this questionniary are predicted some questions regarding the difficiulties and the students' opinon regarding the culture of English languge. 
The first sections of the questionnnare are general date and a very important question: How is distributed the teaching hour for 'teaching of language' and 'teahcing of culture' in the subject of English language during this academic year? This question is important to understand the amount of time dedicated to culture within an hour of lesson.From the answers of the students it is quiet clear that most of the time is dedicated to teaching of language because most of the students have chosen the options $80 \%$ language teaching- $20 \%$ culture teaching or $60 \%$ language teaching - $40 \%$ culture teaching. From the students answers we can understand that culture is mentioned very little during a class and the main objective remains teaching of language. According to the answers of the students they have interest to know more about target culture but unfortunately it is not dedicated much time by the lecturers.

$90 \%$ of the students do not travel to the English-speaking countries. This may come because there are no exchange programs for the students in the English-speaking countries, but also because of the economic conditions of the families. These two factors may not allow contacts with individuals of target culture. None of the students have ever done a language course in English-speaking countires. Going on language courses in the English-speaking countires helps a lot to understand the target culture by being in direct contact with it. Both exchange programms and language courses in the country of target languge, will help to create a positive image and attitude towards other cultures.

Regarding the contacts with media (through newspaper, television, radio) we can say that a very low number of $15.5 \%$ watch TV from the English-speaking countries. In fact, watching TV or reading the newspaper helps to make comparsion with their culture, and in most of the time it effects to be open-minded and to accept other cultures.

In order to understand how much knowledge they have reagarding the the English culture, they were given several question to choose on of the atleratives that they consider more appropriate (1. A lot 2. Sufficient 3. A little 4. Not at all). The topics offered are:

\begin{tabular}{|ll|}
\hline 1. & History, geography, political system \\
\hline 2. & Different ethnic and social groups \\
\hline 3. & Common life and routine, living conditions, food, beverages etc \\
\hline 4. & Youth culture \\
\hline 5. & Education, professional life \\
\hline 6. & Traditions, folklore, touristic attractions \\
\hline 7. & Literature \\
\hline 8. & Other cultural aspects (music, drama, art) \\
\hline 9. & Values and religious believes \\
\hline $\begin{array}{l}\text { 10. } \\
\text { countries }\end{array}$ & International relation (politics, economic and cultural), of the students with students from other \\
\hline
\end{tabular}

The results show that students are not equipped with the necessary knowledge reagarding the culture. The topics which they have very little information are: Values and Religious believes and Different ethnic and social groups. The topic which they have sufficient information: Common life and routine, living conditions, food, beverages etc. The reason why they may have more knowledge in this topic is because they are dealt in their English books.

Regarding the question how often are in contact with foreign culture/people/country realted to English languge they were given 5 questions to choose one of the alternatives( often, rarely, not at all) they consider as more appropriate for them.

1. Contacts with media (through newspapers, television, radio)

2. Visit at the cultural institutions that represent the foreign state in my country

3. Contacts with people with origin from the foreign country but who live in my country

4. Contacts with English professors at your education institution. 5 Contacts with lecturers or foreign students who visit my school 
The data clearly show that they have not at all conctacs with cultural institution that represent the foreign state in the country. Regarding the contacts with English lecturers, the university offers the opportunity to have contacts with foreign lecutres because of the exchange programms for the lectures, but these are limited.

In an open question they were asked to specify other contacts they already have. Some of them have mentioned:

"Our university organizes every year the International Day, where we students present different cultures, and one of them is the English culture'

"Contacts with non Albanian friends from the social website'

"I have contacts only with my English lecutres at my university"

"Very rarely I encounter tourist in the street and I creat somehow contacts with them"

"Through the conferences that our schools organized I have the opportunity to meet people form other countires"

"My cousins are married in UK and I have contacts with their friends"

"My best friend lives in UK and I have opportunity to meet other English people"

"I work in a Travel agency and we have English assistants"

These were some of the answers the students while the rest of the students don't have contacts at all. Having contacts with other individuals gives the students the opportunity to do research on their own regarding their culture in order to have a successful communication.

\section{Conclusions}

As a result of globalization, the mobility of people from one country to the other for different reasons such as work, school etc. people encounter individual of other culture. In order to have an efficient communication is not enough just to speak the target language but also to be able to understand target culture. What do the data suggest? It is very necessary to make changes in the curriucla, where it is dedicate more time to the culture than $20 \%$ or $40 \%$ as it resulted from the data. There is a need for integarating culture and language at the same time in the curricula.

Secondy, these data show that students have lack of knowledge regarding the culture of English-speaking countires; it is now time to bring innovation in the methodology of teaching, and language and culture to be interrelated within the teaching hours. Professors need to work hard on the topics that the students have lack of knowledge. The professors are the one that should encourage comparison between culture, to analyse them independently and to bring different ideas in the classroom.

\section{Reference}

[1] Alptekin, C. (2002). Towards intercultural communicative competence. ELT Journal

[2] Brown, A.V. (2009). Students' and teachers' perceptions of effective foreign language teaching: A comparison of ideals. The Modern Language Journal,

[3] Byram, M.(1989). Cultural Studies in Foreign Language Education. Clevedon: Multilingual Matters.

[4] Byram, M., Gribkova, B., Starkey, H.Council of Europe. (2002). Developing the intercultural dimension in language teaching a practical introduction for teachers.

[5] Hinkel,E (Ed.). Culture is Second Language Teaching and Learning, Cambridge. New York;Cambridge Univeristy Press.

[6] Kramsch,C.(1998). Language and Culture: Oxford University Press 
[7] Lazar,I., Huber-Kriegler,M., Lussier,D., S.Matei,G., Peck,Ch. Developing and assessing intercultural communicative competence: A guide for language teachers and teacher educators

[8] Lies.,Sercu.(2005) Foreign language Teachers and Intercultural competence: An International Investigation

[9] Lewis, Kimberly A. (2014) Adult Learners' perception of the significance of culture in foreign language teaching and learning; Journal of Education and Traing studies

[10] Moeller J. A., Nugent, K. Building intercultural competence in Language Classroom, University of Nebraska

[11] Ryan., Phyllis,M., Lies., Sercu. Foreign language teachers and their role as mediators of language-and-culture: A study in mexico

[12] Roberts, C., Michael,B., Ano,B., Shirley,J.,\&Brian,S. (2001). Language Learners as Ethnographers. Clevedon: Multilingual Matters.

[13] R. Michael Paige, Jorstad,H., Siaya,L., Klein,F,. Colby J. Culture Learning in Language Education: A Review of the

[14] Yilmaz, D., Culture In English Language Classrooms: What Do Students Think? Bogayici Univeristy, Turkey 